\title{
The Effect of Greenhouse Gases on Earth's Temperature
}

\author{
Ahmad L. El Zein ${ }^{1}$, Nour A. Chehayeb ${ }^{2, ~ *}$ \\ ${ }^{1}$ Corporate Relations Office, Modern University for Business and Science, Beirut, Lebanon \\ ${ }^{2}$ Faculty of Education, Modern University for Business and Science, Beirut, Lebanon \\ Email address: \\ ahmad.elzein@hotmail.com (A. El Zein), nourchehayeb94@hotmail.com (N. A. Chehayeb)
}

\section{To cite this article:}

Ahmad El Zein, Nour Chehayeb. The Effect of Greenhouse Gases on Earth's Temperature. International Journal of Environmental Monitoring and Analysis. Vol. 3, No. 2, 2015, pp. 74-79. doi: 10.11648/j.ijema.20150302.16

\begin{abstract}
Global warming is affecting each and every part of the world. Due to global warming, the glaciers are melting which are causing the rise in the sea level. When the level of the sea rises, it causes danger to the people living in the low lying areas. So, this causes a big problem for people, plants and animals living on the earth or the ecosystem all in all. Pollution whether vehicular, electrical or industrial is the main contributor to the global warming. Everyday billions of vehicles release various gases into the atmosphere. This causes earth to warm up and increase its average temperature. The main purpose of the study is to collect information about a real problem that has negative impact on something in order to be able to reach solution or decrease its impact. This study shows that global warming is the result of many factors including greenhouse gasses which can be reduced if people behave in a responsible way. We can state that pollution is the link between the greenhouse gases released to the air and get trapped in the atmosphere which cause the raise in temperature known as global warming and leading to a huge bulk of negative consequences to all living and non-living creatures on Earth's surface.
\end{abstract}

Keywords: Green House, Global Warning, Gases, Environment

\section{Introduction}

Many companies engaged in the business field neglect operation standards that enhance the quality of environment and protect it. Quality principles ensure that companies will provide customers with healthier and cleaner products. Add to that, the high population and the absence of control in the construction companies lead to global warming and environmental problems.

For that reason, the importance of spreading awareness and consciousness about global environmental problems such as global warming, ozone depletion and pollution is crucial for such companies.

The world is witnessing changes in its weather due to many troubles in the environment. The unplanned use of the environmental resources has lead to a ruined life cycle since humans are cutting high number of forests in order to construct cities. Global warming is one of the biggest problems facing our Earth nowadays due to the misuse of energy and resources; and therefore leading to serious modulation in its heat. The change in the warm of the earth is changing the life cycle of all creatures (Riebeek, 2010).

The fast growth of population is increasing the expansion of urban randomly without any plan which is harming the environment and nature. Planning process, while constructing cities, is very important due to its role in using the spaces efficiently taking into consideration the protection of green lands. People are using the resources in a way that lacks awareness about risks of wasting the natural resources and energy, and about the negative impact of wasting the raw material on the future term.

People's daily activities require the usage of a lot of petroleum and electrical consumption that increases air pollution which threatens human lives and environment causing expensive health and medication bills. Many scientists and economists are trying to find a solution for pollution and greenhouse gasses through replacing the existing products with green and renewable products.

\section{Literature Review}

\subsection{Global Warming}

Global warming involves the increase in the Earth's temperature, which might have serious and dangerous repercussions on the Earth's inhabitants, be it human beings, animals or plants. Global warming is caused by many factors. The causes are divided into two groups, natural causes and man-made causes (Hofstrand, 2013). 
The first cause of the global environment refers to the natural causes. Since the change of one factor in the earth affects the whole system of warming. The climate system combines the different natural elements on earth and links them together forming the safe place. The Climate System consists of: The atmosphere, the oceans, the land, the ice caps, and the biosphere. Because climate is everywhere it must be normal, neither cool nor warming. Since human are all affected by it, everyone must knows which gases involves in changing the climate into warming which affect the life. This is very difficult to predict but may include the factors that increase the carbon dioxide: Tundra, Water vapor in the atmosphere increasing, carbon dioxide and other greenhouse gas variations, solar variations, volcanic eruptions, Ocean circulation, Orbital variations, Permafrost, Climate change, Greenhouse gas. About 50 billion tons of carbons are estimated to be held in a frozen state in the tundra is beginning to become a source of carbon dioxide (Masih, 2010).

Since water vapor is an important factor in the atmosphere increasing, it is the most spread and powerful greenhouse gas on earth, but its increase leads to the warming caused by carbon dioxide, methane and other greenhouse gases. Moreover, the ocean circulation which is the result of temperature change can be considered the main factor in heat transportation. The melting of the ice mountain increases the fresh water in a way that changes the ocean circulation. This is a natural cause in global warming. As it's known, water vapor is a step in the ocean circulation. In fact, the ocean plays an important role in determining the atmospheric concentration of carbon dioxide. Changes in ocean circulation may effect to climate by slowly moving carbon dioxide into or out of the atmosphere.

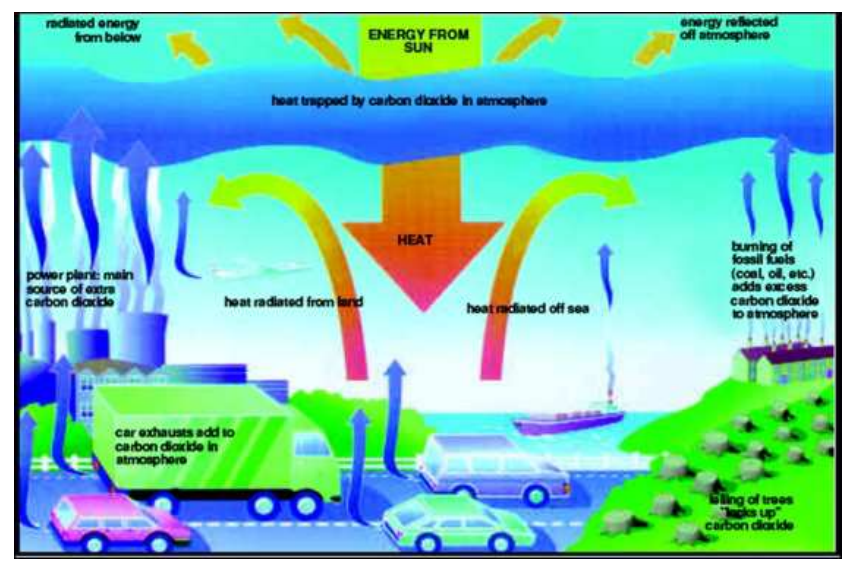

Figure 1. http://www.climate-change-knowledge.org

Many gases and most importantly the water vapor and carbon dioxide contribute to the greenhouse effect that warms the earth's surface. Few scientists suspect that a portion of the warming in the first half of the 20th century was due to an increase in the output of solar energy (Hansen, et al., 1999).

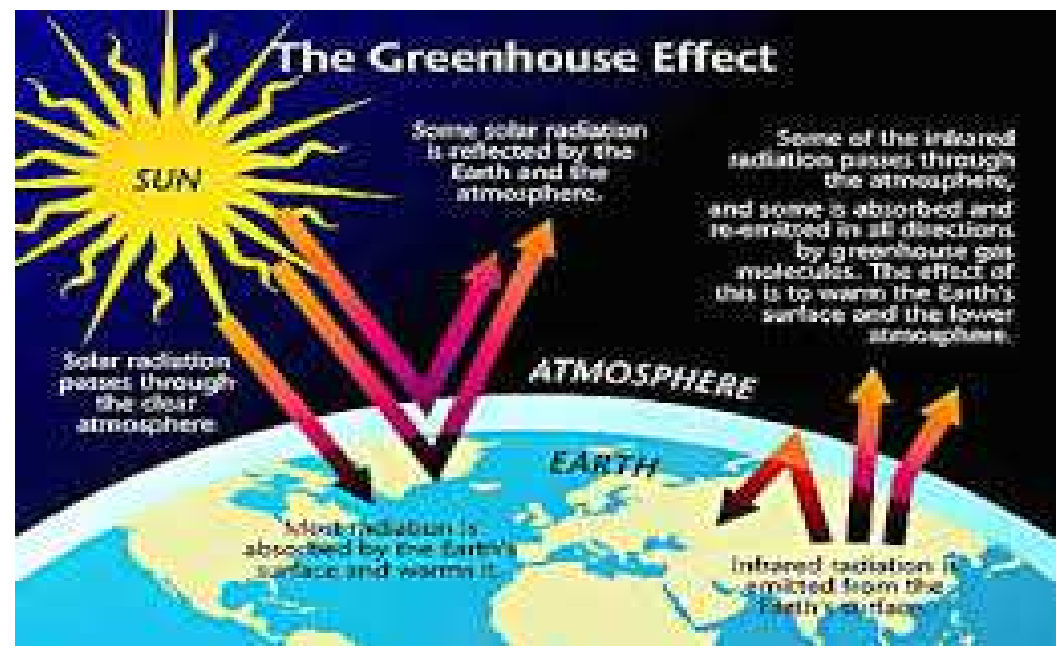

Figure 2. www.realscience.org.uk

An important natural cause refers to the orbital variation since slow changes in the earth's orbit lead to small but climatically important changes in the strength of the seasons over tens of thousands of years. Another cause in the global warming refer to the rising temperature which could badly affects the constructions in permafrost by causing damages to buildings, electric generating stations, pipe lines \& other structures because the instability of the ground would cause erosion to affect the terrain, roads and others. The Permafrost is frozen soil situated deeply in the land in a way that represents approximately 25 percent of the surface. In case of warming, the buildings may be destroyed permitting the methane to release into the atmosphere

The global warming is the result of the climate change which affects all the above factors. As global warming and related climate changes become accepted libraries to have it is increasingly important for, as scientific fact resources that inform about these serious global issues. Brenda $\mathrm{w}$ lemer and $\mathrm{k}$ signed 250 volume reference works of contributors to create two entries on the scientific causes and global consequences of climate order to understand the essential facts of topics and change in issues related to the scientific 
study of climate change and its impact on humanity (Masih, 2010).

Table 1. Gases forming the Greenhouse gas

\begin{tabular}{|c|c|c|c|c|c|c|c|c|c|}
\hline Chemical Species & & & & Sources & & & & & \\
\hline Name & Formula & Concentration & Residence Time & Biogenic & Anthropogenic & Photochemical & Volcanic & Radiogenic & other \\
\hline Nitrogen & N2 & $78.084 \%$ & $1.6 \times 10^{7}$ Years & $\checkmark$ & & & $\checkmark$ & & \\
\hline Oxygen & $\mathrm{O} 2$ & $20.946 \%$ & $3 \times 10^{3}-10^{4}$ Years & $\checkmark$ & & & & & \\
\hline Argon & $\mathrm{Ar}$ & $0.934 \%$ & & & & & & $\checkmark$ & \\
\hline Water Vapor & $\mathrm{H} 2 \mathrm{O}$ & $0-4 \%$ & 10 Years & $\checkmark$ & $\checkmark$ & & $\checkmark$ & & 1 \\
\hline Carbon Dioxide & $\mathrm{CO} 2$ & $3.94 \times 10^{-2} \%$ & 20-150 Years & $\checkmark$ & $\checkmark$ & & $\checkmark$ & & \\
\hline Neon & $\mathrm{Ne}$ & $1.818 \times 10^{-3} \%$ & & & & & $\checkmark$ & & \\
\hline Helium & $\mathrm{He}$ & $5.24 \times 10^{-4} \%$ & $10^{7}$ Years & & & & & $\checkmark$ & \\
\hline Methane & $\mathrm{CH} 4$ & $1.79 \times 10^{-4} \%$ & 10 Years & $\checkmark$ & $\checkmark$ & & & & \\
\hline Krypton & $\mathrm{Kr}$ & $1.14 \times 10^{-4} \%$ & & & & & & $\checkmark$ & \\
\hline Hydrogen & $\mathrm{H} 2$ & $5.3 \times 10^{-5} \%$ & 2 Years & $\checkmark$ & $\checkmark$ & & & & 2 \\
\hline Nitrous oxide & $\mathrm{N} 2 \mathrm{O}$ & $3.25 \times 10^{-5} \%$ & 150 Years & $\checkmark$ & $\checkmark$ & & & & \\
\hline Carbon-monoxide & $\mathrm{CO}$ & $5-25 \times 10^{-6} \%$ & $0.2-0.5$ Years & $\checkmark$ & $\checkmark$ & & & & \\
\hline Xenon & $\mathrm{Xe}$ & $8.7 \times 10^{-6} \%$ & & & & & & & \\
\hline Ozone & $\mathrm{O} 3$ & $1-5 \times 10^{-6} \%$ & Weeks-months & & & $\checkmark$ & & & \\
\hline Nitrogen-dioxide & $\mathrm{NO} 2$ & $0.1-5 \times 10^{-7} \%$ & $8-10$ days & $\checkmark$ & $\checkmark$ & $\checkmark$ & & & \\
\hline Ammonia & NH3 & $0.01-1 \times 10^{-7} \%$ & 5 days & $\checkmark$ & $\checkmark$ & & & & \\
\hline Sulphur-dioxide & $\mathrm{SO} 2$ & $0.003-3 \times 10^{-7} \%$ & 2 days & & $\checkmark$ & $\checkmark$ & $\checkmark$ & & \\
\hline Hydrogen-sulphide & $\mathrm{H} 2 \mathrm{~S}$ & $0.01-6 \times 10^{-8} \%$ & 0.5 day & $\checkmark$ & $\checkmark$ & & $\checkmark$ & & \\
\hline
\end{tabular}

Greenhouse gas is a natural cause in the global warming; it is the result of absorbing the surface radiation released by the earth. The greenhouse gas is represented by several gases: water vapor $\left(\mathrm{H}_{2} \mathrm{O}\right)$, carbon dioxide $\left(\mathrm{CO}_{2}\right)$, nitrous oxide $\left(\mathrm{N}_{2} \mathrm{O}\right)$, methane $\left(\mathrm{CH}_{4}\right)$, ozone $\left(\mathrm{O}_{3}\right)$, chlorofluorocarbons. These gases absorb the radiation which creates energy that released into the atmosphere.

A warming global climate believed to be due to the accumulation of greenhouse gases in the atmosphere and caused by the release of manufacture and human activities. The human activities includes: Deforestation, Methane, carbon dioxide from cars, carbon dioxide from power plant, human activity and green house gases, land use changes, greenhouse effect and carbon dioxide.

Deforestation is the second main reason of atmospheric carbon dioxide. It is also responsible for a large amount of carbon entering the atmosphere, and resulting from the burning and cutting of about millions of trees each year which refer to the human activities in order to get their needs from wood, While Methane is the second principal greenhouse gas and more than 20 times as effective as carbon dioxide at preventing heat from escaping in the atmosphere, it is the other solid sediments at the ocean which can be classified as natural cause for the global warming. The increase of the ocean floor temperature leads to the melting of this icy solid causing methane bubbles that released into the atmosphere in order to change the climate.

The third cause is carbon dioxide from cars which is divided to two types; about $33 \%$ of carbon dioxide is emitted by the burned gasoline of light vehicles which are a partial cause of global warming. Sports utility vehicles used in cities are very harmful to the environment. Moreover, Electricity is generated thanks to the burning of fossil fuels, which emits carbon dioxide. One of the main constituents of carbon dioxide is coal, which is very toxic for the environment. Therefore, as noticed, The world's economy depends on "fuel" that provides energy to the largest number of people in industrialized nations, and then its carbon dioxide burning emits the carbon dioxide that contributes more to the recent increase in greenhouse warming than any other gas. This permit for the Urban environments to create lands of heat due to industry, buildings, vehicles, and the absorption of solar energy by dark-colored surfaces. Deforestation can greatly increase in the atmosphere the amount of carbon dioxide which warms the planet (Leggett, 2000).

Due to man-made energy represented by the industrial revolution which leads to the increase in the carbon dioxide, the earth's greenhouse effect is doubled. Human activity is the essential factor in changing the important green house gases. However, Carbon dioxide can be classified in both natural causes and man-made causes since it is obtained from the complete oxidation, from cars (light cars and sports utility vehicles), and from power plants. The concentration of carbon dioxide caused the climate change leading to global warming.

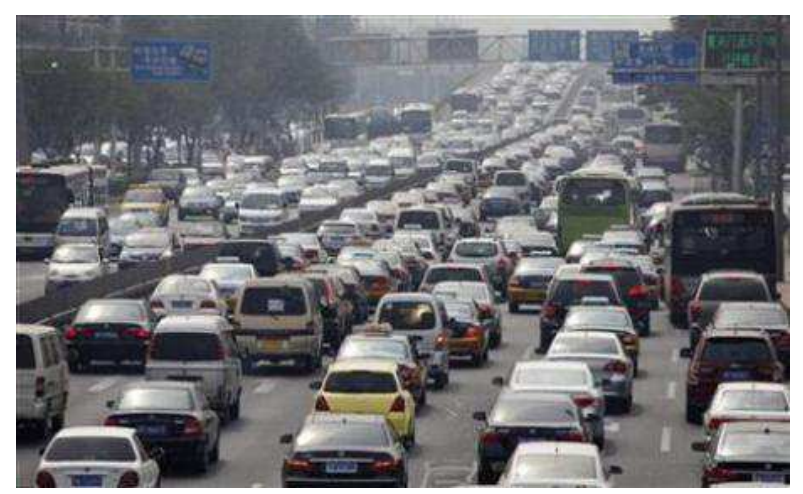

Figure 3. http://www.reuters.com

\subsection{Pollution}

One of the greatest problems that the world is facing today 
is that of environmental pollution, increasing with every passing year and causing grave and irreparable damage to the earth. Environmental pollution consists of five basic types of pollution, namely, air, water, soil, noise and light.

Air pollution is by far the most harmful form of pollution in our environment. Water pollution caused industrial waste products released into lakes, rivers, and other water bodies, has made marine life no longer hospitable. Humans pollute water with large scale disposal of garbage, flowers, ashes and other household waste. In many rural areas one can still find people bathing and cooking in the same water, making it incredibly filthy. Noise pollution, soil pollution and light pollution too are the damaging the environment at an alarming rate.

\section{Greenhouse Gas}

In the last century the effect of greenhouse gasses raised dramatically resulting in what is known as global warming, which is the increase of average temperature of earth which in turn has enormous problems if net treated firmly. Hence, as the average temperature of earth increases the temperature in both poles increases, resulting in melting of the icebergs, and raising ocean water level, which will cause horrible storms and tsunamis. When sun's light reaches earth in a snow or ice aria 80 percent of the light is reflected meanwhile when it reaches earth or water only 20 percent is reflected and the 80 percent is absorbed, this phenomenon is also responsibility for global warming (Houghton, 2004). And along side comes the rise in sea level which is expected to be as 7 meters thus, eliminating many cities around the world, from the universal map, including Beirut.

Green house gas is a gas that absorbs energy which radiates from the surface or atmosphere of the earth or another planet. The principal greenhouse gases are water vapor, carbon dioxide, nitrous oxide, methane, ozone, chlorofluorocarbons, and hydro fluorocarbons. Each gas absorbs at particular wavelengths, and where the wave bands of two or more gases. The amount of radiation absorbed by each gas varies greatly and is reported as its global warming potential. At certain wavelengths, known as the atmospheric window, no outgoing radiation is absorbed (Eastwood and Lipton, 2010).

It is individual gas molecules that absorb the radiation. It imparts energy to them that they then reradiate. Radiation can be absorbed only if it encounters an appropriate molecule in its passage through the atmosphere and into space. The amount of energy absorbed therefore depends on the concentration of those molecules: the higher the concentration, the greater the chance of an impact. It follows that as the atmospheric concentration of particular greenhouse gas increases, so does the amount of radiation that gas absorbs. Once the concentration reaches a level at which all the radiation at the wavelengths absorbed by that gas is being absorbed, however, adding more of the gas will have no effect. This means there is a limit to the possible magnitude of any greenhouse effect.

\section{Enhanced Greenhouse Effect}

There is strong evidence that the earth's greenhouse effect has been strengthened as a result of human activity over the last 250 years or so. Observations confirm that the concentration of carbon dioxide has increased by more than 35 per cent since the start of the industrial revolution in the mid $18^{\text {th }}$ century. During the same period, concentrations of two other important greenhouse gases have increased because of human activity -methane has more than doubled, and nitrous oxide has increased by about 20 per cent. These rates of increase are very unusual-levels of all three gases were more or less constant for thousands of years before the industrial revolution, but are higher today than they have been of hundreds of thousands of years (Houghton, 1997). The impact these gases have on climate varies, depending on their lifetime, abundance in the atmosphere and potency. Carbon dioxide is the most abundant manmade greenhouse gas. A molecule of carbon dioxide released into the air will last about 100 years, while methane has a lifetime of about 12 years and is much less abundant, but one molecule is about 30 times more potent than one of carbon dioxide. Water vapor is the most abundant greenhouse gas, but its concentration is not directly affected by human activity. Greenhouse gases absorb outgoing terrestrial radiation and re-emit it in all directions-some of it back towards the earth to increase temperatures in the lower atmosphere. Concentration of carbon dioxide has increased over the last few centuries due to the burning of fossil fuels and land-use changes, including large-scale deforestation. concentration of methane have risen due to biomass burning, landfill, and increased cattle and rise farming; those of nitrous oxide due to fertilizer use and biomass burning (Costello, et al. 2009).

The Greenhouse effect is the rise in the temperature of the Earth's atmosphere due to certain gases like, methane, water vapor, nitrous oxide and carbon dioxide, which trap the energy and heat from the sun. Without these gasses, the heat would escape reducing the temperature of the atmosphere. These gases are commonly known as Greenhouse gases, because they help to maintain the Earth's average temperature. It is a natural process which makes the Earth's atmosphere just right for life forms to flourish.

In the Earth's atmosphere the Greenhouse gases behave similar to the glass panels in a greenhouse. Sunlight penetrates through Earth's atmosphere, passing through the layer of Greenhouse gases. On reaching the Earth's surface, biosphere, water, and land, absorb the sunlight's heat and energy. Once the energy and heat is absorbed, it returns to the atmosphere. Most of the heat and energy is trapped in the Earth's atmosphere by the Greenhouse gases, which ultimately results in the Earth to warm up; however some of the heat and energy returns back to space.

The Greenhouse effect can also be compared to the inside of a car parked in sunlight, which lets the light in, but traps the heat and energy, keeping the car warm. The Greenhouse effect is very essential, without which the Earth would not be warm enough for humans to survive. 
Today, the term, Greenhouse effect mistakenly signifies the unnatural rise in temperature within the planet's atmosphere due to man-made hazards. If the effect becomes stronger, then the Earth's atmosphere could become warmer than the average temperature. Even a little excess warming may result in trouble for humans, animals and plants.

\section{Modeling the Causes}

In a 2007 report, the intergovernmental panel on climate change (IPCC) very clearly attributed a cause to recent climate change, stating that "it is very likely that anthropogenic greenhouse gas increases caused most of the observed increase in global temperatures since the mid $20^{\text {th }}$ century". Climate models play a key role in revealing the causes of this change. Simulations can be run with different variables that affect climate, and these may be compared with observed data. For example changes in man-made greenhouse gases and aerosols can be omitted to see how they affect temperature. In this way, it is possible to see whether the increase in temperature can be explained by natural variability-such as changes in solar output, volcanic activity, or internal variability- or by human interference in the climate system. If, when all plausible factors are included, the match with observed data is good; this gives confidence that the model is accurate (Hansen, et al., 1999).

\section{Ocean Circulation Change}

The global circulation of the oceans- known as the thermohaline circulation, which is driven by differences in temperature and salinity- is an important means of transporting heat from the topics to higher latitudes. Scientists believe that the increasing supply of fresh water to the northern North Atlantic, from melting ice sheets and increased rainfall, could influence the ocean circulation. Less dense fresh water at the surface may lead to the slowing, or even shutting down, of this important system of heat transport. This could result in the cooling of the climate in large parts of Europe, although scientists do not believe this will occur this century, and a total shutdown is very unlikely (Benarde, 1992).

\section{Methane Release}

Methane clathrate is icy solid sediments at the bottom of the ocean. There is a huge store of this compound under the oceans today, and it is thought that the substance may have caused rapid climate changes in the past. Warmer sea floor temperatures may result in the melting of this icy solid, causing a rapid increase in the number of methane bubbles rising through the oceans and being released into the atmosphere. Methane is a powerful greenhouse gas, and a jump in its concentration in the atmosphere could result in sudden climate change.

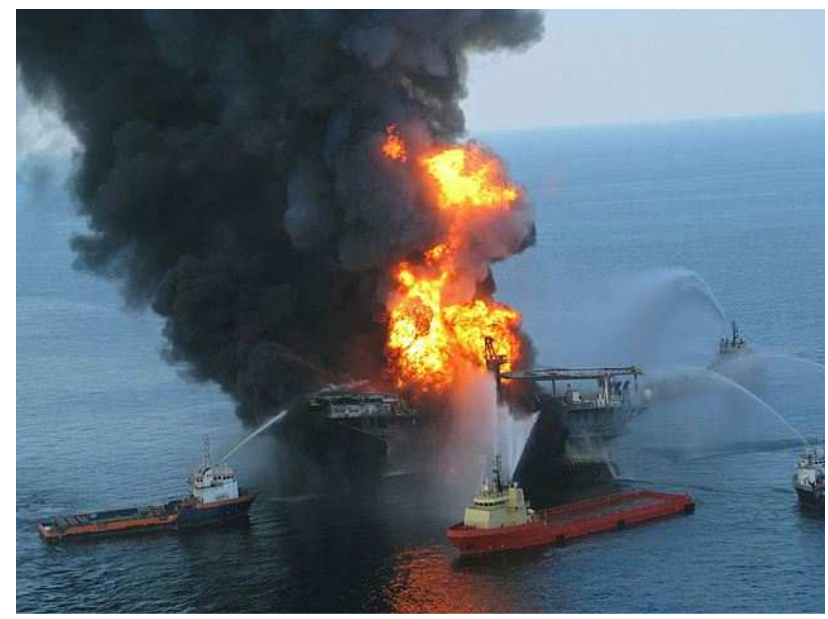

Figure 4. www.oceanminds.com

\section{Melting Permafrost}

Permanently frozen soil, known as permafrost lies under large tracts of land in the high-latitude regions of the northern continents, accounting for between 20 and 25 per cent of the earth's land surface. In recent years, warming has led to more widespread thawing of the upper layers in some places. As a result, some buildings have collapsed and pipelines have fractured. More importantly, thawing has caused the release of methane into the atmosphere, accelerating global warming

Warming across high, northern continental areas has led to the thawing of permafrost. As a result, buildings have been damaged and stored methane has been released into the atmosphere.

Carbon dioxide

A gas formed by the complete oxidation of the carbon that is a minor constituent of the atmosphere. It is the most important greenhouse gas and climatic changes in the past have been associated with changes in the atmospheric concentration of carbon dioxide (Moll, 2014).

Carbon dioxide is a natural compound composing from two oxygen atoms bonded to a carbon atom it exists in earth's atmosphere in the gases state. It is responsible for $60 \%$ of the green house effects. Greenhouse effect by definition is when earth blocks the heat radiations absorbed by earth, throughout the day, and prevents it from returning to the space during the night, thus raising earth's temperature (Benarde, 1992).

\section{Conclusion}

As conclusion, global warming is a challenging problem that necessitates immediate treatment. The causes are many and are mainly divided into two groups: the natural and the man-made. Although they might be difficult to deal with, it is not impossible to reduce them.

Nowadays, more importance is being aimed at the environment and the various ways that can contribute to save the earth that is considered as a home to all the humans. A major factor that can help with this issue is waste 
management and recycling which is the topic of this project. Waste management is broad term that includes many implications that goes from reducing waste, reusing and recycling all kinds of waste like glass, paper, aluminum, plastic, iron and other elements in order to increase the green gasses effect on earth. In addition, the increase of awareness of people to practice waste management can play a major role in this issue.

The first challenge is eliminating the burning of coal, oil and, eventually, natural gas. This is perhaps the most daunting challenge as denizens of richer nations literally eat, wear, work, play and even sleep on the products made from such fossilized sunshine. And citizens of developing nations want and arguably deserve the same comforts, which are largely thanks to the energy stored in such fuels.

Oil is the lubricant of the global economy, hidden inside such ubiquitous items as plastic and corn, and fundamental to the transportation of both consumers and goods. Coal is the substrate, supplying roughly half of the electricity used nearly worldwide a percentage that is likely to grow, according to the International Energy Agency. There are no perfect solutions for reducing dependence on fossil fuels (for example, carbon neutral bio-fuels can drive up the price of food and lead to forest destruction, and while nuclear power does not emit greenhouse gases, it does produce radioactive waste), but every bit counts.

Moreover, Buildings worldwide contribute around one third of all greenhouse gas emissions, even though investing in thicker insulation and other cost-effective, temperatureregulating steps can save money in the long run. And bad roads can lower the fuel economy of even the most efficient vehicle. Investing in new infrastructure, or radically upgrading existing highways and transmission lines, would help cut greenhouse gas emissions and drive economic growth in developing countries.

The easiest way to cut back on greenhouse gas emissions is simply to buy less stuff. Whether by forgoing an automobile or employing a reusable grocery sack, cutting back on consumption results in fewer fossil fuels being burned to extract, produce and ship products around the globe.

Think green when making purchases. For instance, if the person is in the market for a new car, he should buy one that will last the longest and have the least impact on the environment. Thus, a used vehicle with a hybrid engine offers superior fuel efficiency over the long haul while saving the environmental impact of new car manufacture.

Climate change represents humanity's first planet wide experiment. But, if all else fails, it may not be the last. Socalled geo-engineering, radical interventions to either block sunlight or reduce greenhouse gases, are a potential last resort for addressing the challenge of climate change.

\section{References}

[1] Benarde. M. A. (1992) Global Warning ... Global Warming. New York: Wiley.

[2] Costello A, Abbas M, Allen A, et al. (2009). Lancet and UCL Institute for Global Health Commission: managing the health effects of climate change. Lancet 2009; 373: 1693 - 733.

[3] Eastwood R, Lipton M. (2010). The impact of changes in human fertility on poverty. J Dev Stud 1999;36:1-30

[4] Houghton.J. (1997). Global Warming: The Complete Briefing. New York: Cambridge University Press.

[5] Hansen J, Ruedy R, Glascoe J, Sato M. 1999 GISS analysis of surface temperature change. J. Geophys. Res.104, 30997.

[6] Hofstrand, D. (2013). Global warming - impact on greenhouse gases. IOWA State University.

[7] Leggett. J. (2000). The Carbon War: Global Warming at the End of the Oil Era. London: Penguin.

[8] Masih, J. (2010). Causes and Consequences of Global Climate Change. Scholars Research Library.2 (2):100-108

[9] Moll, E. (2014). Greenhouse Effect on the Climate and Global Warming. Home guides : SF gate

[10] Riebeek, H. (2010). Global Warming. earthobservatory.nasa.gov 